\title{
Black Chokeberry (Aronia melanocarpa (Michx.) Elliot) Fruits and Functional Drinks Differ Significantly in Their Chemical Composition and Antioxidant Activity
}

\author{
Petko Denev $(\mathbb{D}$, Maria Kratchanova, Ivalina Petrova, Daniela Klisurova, \\ Yordan Georgiev, Manol Ognyanov $\mathbb{D}$, and Irina Yanakieva \\ Laboratory of Biologically Active Substances, Institute of Organic Chemistry with Centre of Phytochemistry, \\ Bulgarian Academy of Sciences, 139 Ruski Blvd., 4000 Plovdiv, Bulgaria \\ Correspondence should be addressed to Petko Denev; petkodenev@yahoo.com
}

Received 14 May 2018; Revised 20 September 2018; Accepted 2 October 2018; Published 1 November 2018

Academic Editor: Davide Barreca

Copyright (c) 2018 Petko Denev et al. This is an open access article distributed under the Creative Commons Attribution License, which permits unrestricted use, distribution, and reproduction in any medium, provided the original work is properly cited.

\begin{abstract}
Black chokeberry (Aronia melanocarpa) fruits are among the richest sources of polyphenols and anthocyanins in plant kingdom and suitable raw material for production of functional foods. The popularity of chokeberries is not only due to their nutritional value but also to the constantly emerging evidence for their health-promoting effects. The current study presents detailed information about the content and composition of sugars, organic acids, and polyphenols in 23 aronia samples grown under the climatic conditions of Bulgaria, in 2016 and 2017. Sorbitol was found to be the main carbohydrate of fresh aronia fruits. Its content was in the range $6.5-13 \mathrm{~g} / 100 \mathrm{~g}$ fresh weight (FW), representing $61 \%-68 \%$ of low-molecular-weight carbohydrates. Organic acids were represented by substantial amounts of quinic acid (average content $404.4 \mathrm{mg} / 100 \mathrm{~g} \mathrm{FW}$ ), malic acid (328.1 mg/100 g FW), and ascorbic acid $(65.2 \mathrm{mg} / 100 \mathrm{~g} \mathrm{FW})$. Shikimic acid, citric acid, oxalic acid, and succinic acid were found as minor components. Chokeberries were particularly rich in proanthocyanidins, anthocyanins, and hydroxycinnamic acids. The total polyphenol content of aronia fruits varied between $1022 \mathrm{mg} / 100 \mathrm{~g} \mathrm{FW}$ and $1795 \mathrm{mg} / 100 \mathrm{~g} \mathrm{FW}$ and ORAC antioxidant activity from $109 \mu \mathrm{mol}$ $\mathrm{TE} / \mathrm{g}$ to $191 \mu \mathrm{mol} \mathrm{TE} / \mathrm{g}$ FW. We also investigated the relationship between the chemical composition of berries and chemical compositions and antioxidant activity of aronia functional drinks-juices and nectars. The differences in the chemical composition of the fruits resulted in functional foods that differ significantly in their chemical composition and antioxidant activity. Additionally, we demonstrated that temperature of juice pressing and nectar extraction has a profound effect on the polyphenol content and composition of these products. This is very important since differences in the chemical composition of raw chokeberries and variation of technological parameters during processing could result in functional foods with different chemical composition, rendering different biological activity.
\end{abstract}

\section{Introduction}

The food is a source not only of nutrients and energy for the living organisms but also of a broad spectrum of nonnutritive biologically active compounds. A growing amount of evidence demonstrates that the consumption of fruits, vegetables, and herbs is associated with a lower risk of arteriosclerosis and other oxidative stress-related diseases [1]. Among plant foods, berries are characteristic with high content of bioactive substances, including polyphenols. Therefore, they are suitable raw materials for the development of functional drinks $[2,3]$, which is the main reason for the substantial scientific interest in polyphenol-rich berries, in the last years. In search of promising sources of natural antioxidants, black chokeberry (Aronia melanocarpa, Rosaceae) is very appropriate since it is among the richest sources of polyphenols in the plant kingdom $[4,5]$. It originates from North America, and in the 1900s, it was introduced to Europe. In the past, it was cultivated mostly as an ornamental plant and used for domestic production of juices, wines, jams, etc. Now aronia berries are widely distributed in Europe and cultivated as an important industrial crop [6-8]. It is a valuable raw material for juice and wine industries and it is used as a source of food-grade 
colourant. The high content of different polyphenol compounds and multiple health benefits of chokeberry determine the increasing scientific interest in the fruit and its industrial processing [4]. Several papers reviewed the chemical composition of aronia berries [4, 9], their clinical effectiveness [10], and use for prevention of noncommunicable diseases [11]. Health benefits of chokeberry include hypotensive $[12,13]$, lipid-lowering [14], gastroprotective [15], hepatoprotective [16, 17], and anticarcinogenic effects $[18,19]$. More recently, aronia products and preparations have shown antiviral activity [20], antiaging effect [21], protective effect against cadmium intoxication [22], and anti-inflammatory effect in patients with mildly elevated blood pressure [23]. Furthermore, aronia have also shown potential in the control of type 2 Diabetes [24]. The high content of sorbitol is the most characteristic feature of chokeberry that could be used as a marker for its product authenticity [9]. Besides, this intensively coloured berry is a very rich source of anthocyanins, proanthocyanidins, and hydroxycinnamic acids. Quercetin, quercetin glycosides, and epicatechin are present in the fruits as minor components [4, 9]. Several factors including habitat, cultivar, maturation stage, fertilization, harvest date, etc. could affect the chemical composition of chokeberries [9]. There are several studies on the chemical composition of aronia fruits [25-28] and juices [29]. However, none of them investigates the relationship between the chemical composition of the fruits and the chemical composition and antioxidant activity of functional foods obtained from them. The current study presents detailed information about the content and composition of sugars, organic acids, and polyphenols in 23 aronia samples grown under the climate conditions of Bulgaria. To our knowledge, this is the most comprehensive evaluation of the chemical composition of aronia berries. For the first time, we investigate the relationship between the chemical compositions of aronia berries and chemical compositions and antioxidant activity of aronia functional drinks-juices and nectars. Additionally, we demonstrated that temperature of juice pressing and nectar extraction has a profound effect on polyphenol content and composition of these products. This is very important since differences in the chemical composition of raw chokeberries and variation of technological parameters during processing could result in functional foods with different chemical composition, rendering different biological activity.

\section{Material and Methods}

2.1. Chemicals. Folin-Ciocalteu's phenol reagent was obtained from Merck (Darmstadt, Germany). Cyanidin-3-Ogalactoside chloride, cyanidin-3-O-arabinoside chloride, and cyanidin-3-O-arabinoside chloride were purchased from Extrasynthese S.A. (Genay Cedex, France). Gallic acid, chlorogenic acid, 3,4-dihydroxy benzoic acid, p-coumaric acid, caffeic acid, ellagic acid, ferulic acid, catechin, rutin, naringin, naringenin, epicatechin, myrecetin, quercetin-3glucoside, quercetin, kaempherol, glucose, fructose, sucrose, sorbitol, quinic acid, tartaric acid, malic acid, ascorbic acid, $\alpha$-ketoglutaric acid, citric acid, shikimic acid, oxalic acid, 6-hydroxy-2,5,7,8-tetramethylchroman-2-carboxylic acid (Trolox), fluorescein disodium salt, and 2,2-azobis-(2amidinopropane)dihydrochloride (AAPH) were delivered from Sigma-Aldrich (Steinheim, Germany). All other solvents used were of analytical grade and purchased from local distributors.

2.2. Plant Materials. Altogether, 23 samples of aronia fruits (Nero variety) were supplied from local growers of aronia fruits, in the stage of full maturity, in August 2016 (11 samples) and 2017 (12 samples). Fresh fruits were put in polyethylene bags, frozen, and stored at $-18^{\circ} \mathrm{C}$ until analyzed.

2.3. Extraction of Polyphenols, Proanthocyanidins, and Flavonoids. Briefly, $50 \mathrm{~g}$ of frozen fruits were left to defrost at room temperature and homogenized in a laboratory blender. Approximately $2 \mathrm{~g}$ of the fruit mash were weighed accurately, transferred to extraction tubes and mixed with $40 \mathrm{ml}$ of the extragent ( $80 \%$ acetone solution in $0.5 \%$ formic acid). Extraction was conducted on an orbital shaker at room temperature for one hour. After that, the samples were centrifuged $(6000 \mathrm{x} g$ ) and supernatants were further used for antioxidant activity determination and analysis of anthocyanins, polyphenols, and proanthocyanidins.

2.4. Extraction of Sugars and Organic Acids. One gram of fruit mash was weighed accurately and extracted for 1 hour at $30^{\circ} \mathrm{C}$ with $30 \mathrm{ml}$ distilled water and shaking on a thermostatic water bath (NUVE, Turkey). After that, the samples were centrifuged (6000x $g$ ) and supernatants were used for HPLC analysis of sugars and organic acids.

2.5. Preparation of Aronia Juice and Aronia Nectars. Aronia fruit juices were prepared by the following procedure: $5 \mathrm{~kg}$ of frozen fruits were defrosted at room temperature and homogenized with a laboratory blender. Then, $1 \mathrm{~kg}$ of the mash was transferred in a brown glass bottle and incubated in thermostatic shaker water bath (NUVE, Turkey) for one hour at the corresponding temperature $20^{\circ} \mathrm{C}$, $40^{\circ} \mathrm{C}, 60^{\circ} \mathrm{C}$, or $80^{\circ} \mathrm{C}$. After that, the fruit mash was filtered through cheese cloth and the liquid phase was centrifuged (30 min, $6000 \mathrm{~g}$ ). The obtained juices were denoted as $\mathrm{AJ}_{20}$, $\mathrm{AJ}_{40}, \mathrm{AJ}_{60}$, and $\mathrm{AJ}_{80}$, respectively.

Aronia fruit nectars (40\% fruit content) were prepared by the following procedure: $5 \mathrm{~kg}$ of frozen fruits were defrosted at room temperature and homogenized with a laboratory blender. Then, $320 \mathrm{~g}$ of the mesh were mixed with $480 \mathrm{ml}$ distilled water. Mixtures were transferred to brown glass bottles and incubated in a thermostatic shaker water bath (NUVE, Turkey) for one hour at the corresponding temperatures $20^{\circ} \mathrm{C}, 40^{\circ} \mathrm{C}, 60^{\circ} \mathrm{C}$, or $80^{\circ} \mathrm{C}$. After that, the fruit mash was filtered through cheese cloth and the liquid phase was centrifuged ( $30 \mathrm{~min}, 6000 \mathrm{~g}$ ). The obtained nectars with fruit content $40 \%$ were denoted as $\mathrm{AN}_{20}, \mathrm{AN}_{40}$, $\mathrm{AN}_{60}$, and $\mathrm{AN}_{80}$, respectively. 
2.6. High-Performance Liquid Chromatography (HPLC) Analysis of Sugars. HPLC determination of sugars was performed on an HPLC system (Agilent 1220, Agilent Technology, USA), with a binary pump and refractive index detector (Agilent Technology, USA). The column was ZORBAX Carbohydrate $(5 \mu \mathrm{m}, 4.6 \times 150 \mathrm{~mm}$, Agilent), connected to a guard column ZORBAX Reliance Cartridge (Agilent), eluent $80 \%$ acetonitrile, flow rate $1.0 \mathrm{ml} / \mathrm{min}$, and temperature $25^{\circ} \mathrm{C}$. Results were expressed as $\mathrm{g} / 100 \mathrm{~g}$ fresh weight $(\mathrm{FW})$.

2.7. HPLC Determination of Organic Acids. HPLC determination of organic acids was performed on an HPLC system (Agilent 1220, Agilent Technology, USA), with a binary pump and UV-Vis detector (Agilent Technology, USA). Organic acid separation was performed on an Agilent TC-C18 column $(5 \mu \mathrm{m}, 4.6 \mathrm{~mm} \times 250 \mathrm{~mm})$ at $25^{\circ} \mathrm{C}$ at $210 \mathrm{~nm}$. The mobile phase was $25 \mathrm{mM}$ phosphate $\left(\mathrm{K}_{2} \mathrm{HPO}_{4} / \mathrm{H}_{3} \mathrm{PO}_{4}\right)$ buffer ( $\mathrm{pH} 2.4$ ) flowing at $1.0 \mathrm{ml} / \mathrm{min}$. Results were expressed as $\mathrm{mg} / 100 \mathrm{~g} \mathrm{FW}$.

2.8. HPLC Analysis of Phenolic Compounds. HPLC analysis of phenolic components was performed according to [30] on an HPLC system (Agilent 1220, Agilent Technology, USA), with a binary pump and UV-Vis detector (Agilent Technology, USA). Separation was performed on an Agilent TC-C18 column $(5 \mu \mathrm{m}, 4.6 \mathrm{~mm} \times 250 \mathrm{~mm})$ at $25^{\circ} \mathrm{C}$ and a wavelength of $280 \mathrm{~nm}$ was used. The following mobile phases were used: $0.5 \%$ acetic acid (A) and $100 \%$ acetonitrile (B) at a flow rate $0.8 \mathrm{ml} / \mathrm{min}$. The gradient elution started with $14 \% \mathrm{~B}$, between $6 \mathrm{~min}$ and $30 \mathrm{~min}$, linearly increased to $25 \% \mathrm{~B}$, and then to $50 \% \mathrm{~B}$ at $40 \mathrm{~min}$. Results were expressed as $\mathrm{mg} / 100 \mathrm{~g} \mathrm{FW}$ or per liter juice or nectar.

2.9. HPLC Determination of Anthocyanins. Anthocyanins were determined on an HPLC system (Agilent 1220, Agilent Technology, Palo Alto, Ca), with a binary pump and UV-Vis detector (Agilent Technology, USA). A wavelength of $520 \mathrm{~nm}$ was used. Anthocyanins were separated using an Agilent TC-C18 column $(5 \mu \mathrm{m}, 4.6 \mathrm{~mm} \times 250 \mathrm{~mm})$ at $25^{\circ} \mathrm{C}$. Following mobile phases were used: $5 \%$ formic acid (A) and $100 \%$ methanol (B) at a flow rate of $1.0 \mathrm{ml} / \mathrm{min}$. The gradient condition started with $15 \% \mathrm{~B}$ and linearly increased to $30 \% \mathrm{~B}$ at $20 \mathrm{~min}$. Results were expressed as $\mathrm{mg} / 100 \mathrm{~g}$ FW or per liter juice or nectar.

2.10. Total Polyphenol Compounds Analysis. Total polyphenols were determined according to the method of Singleton and Rossi, with Folin-Ciocalteu's reagent [31]. Gallic acid was used for calibration curve, and results were expressed as gallic acid equivalents (GAE) per $100 \mathrm{~g}$ FW or per liter juice or nectar.

2.11. Total Proanthocyanidin Content Analysis. Total proanthocyanidins were determined according to Sarneckis et al. [32]. Proanthocyanidin content was calculated from a calibration curve with catechin solutions and expressed as catechin equivalent (CE) per $100 \mathrm{~g} F W$ or per liter juice or nectar.

2.12. Total Anthocyanin Content Determination. Total anthocyanin content was determined by the $\mathrm{pH}$ differential method [33].

2.13. Oxygen Radical Absorbance Capacity (ORAC) Assay. ORAC was measured according to the method of Ou et al. [34] with some modifications described in detail by Denev et al. [35]. ORAC analyses were carried out on FLUOstar OPTIMA plate reader (BMG Labtech, Germany) with an excitation wavelength of $485 \mathrm{~nm}$ and emission wavelength of $520 \mathrm{~nm}$.

2.14. Statistical Analysis. The results are expressed as the means from at least three independent experiments \pm standard deviations (SD). Experiments were realized in duplicates or triplicates. Comparisons with the control were performed by analysis of variance (ANOVA), followed by the Newman-Keuls post hoc test. $P$ values less than 0.05 were considered as significant.

\section{Results and Discussion}

3.1. Sugar and Organic Acid Content and Composition of Aronia Fruits. Although the content of organic acids and sugars in plant foods is associated with their taste profile and nutritional value, the available information about the content of these components in aronia berries is scarce. The detailed information about the content and composition of sugars in the investigated 23 aronia samples is given in Table 1, whereas Figure 1 presents the mean value for each individual carbohydrate.

As it is evident from Table 1 and Figure 1, sorbitol is the main carbohydrate present in fresh aronia fruits. Its content in the berries varies in the range 6.6-13 g/100 $\mathrm{g} \mathrm{FW}$, which is always between $61 \%$ and $68 \%$ of the total low-molecular carbohydrates. Other studies also report that sorbitol is the main carbohydrate in aronia berries in amounts from $4.2-10 \%$ on fresh weight basis. However, as it is evident from Figure 1, the average content of sorbitol in Bulgarian chokeberries is $9.39 \%$. It exceeds $10 \%$ in seven of the tested samples, reaching $13 \%$, which is the highest reported value in the literature [36-38]. The second most abundant sugar is fructose, followed by glucose with an average content of $2.86 \mathrm{~g} / 100 \mathrm{~g}$ and $2.00 \mathrm{~g} / 100 \mathrm{~g}$, respectively. Sucrose was detected in 20 samples in amounts up to $0.34 \%$.

Organic acids are another important component of foods since their presence and composition strongly affect food palatability. The amount of individual organic acids in the analyzed 23 aronia samples is presented in Table 2 . Altogether, seven organic acids were detected in fresh aronia berries (quinic acid, malic acid, ascorbic acid, shikimic acid, citric acid, oxalic acid, and succinic acid), whereas $\alpha$-ketoglutaric acid and tartaric acid were not detected. There are just few studies on organic acid content and composition of 
TABle 1: Sugar content (g/100g FW) and composition of 23 samples of aronia berries.

\begin{tabular}{lccccc}
\hline Sample & Fructose & Glucose & Sorbitol & Sucrose & Total \\
\hline 2016_1 & 3.04 & 2.17 & 11.66 & 0.15 & 17.02 \\
2016_2 & 3.14 & 1.66 & 10.79 & 0.22 & 15.81 \\
2016_3 & 3.31 & 1.92 & 10.78 & 0.28 & 16.29 \\
2016_4 & 2.77 & 1.74 & 9.12 & 0.33 & 13.96 \\
2016_5 & 2.86 & 1.62 & 9.01 & 0.23 & 13.72 \\
2016_6 & 3.42 & 1.82 & 11.24 & 0.23 & 16.71 \\
2016_7 & 3.08 & 1.87 & 9.55 & n.d. & 14.50 \\
2016_8 & 2.67 & 1.53 & 8.71 & 0.10 & 13.01 \\
2016_9 & 2.74 & 1.84 & 10.22 & 0.34 & 15.14 \\
2016_10 & 3.09 & 1.90 & 8.74 & 0.41 & 14.14 \\
2016_11 & 2.69 & 1.60 & 7.87 & 0.06 & 12.22 \\
2017_1 & 2.45 & 1.89 & 8.05 & 0.09 & 12.48 \\
2017_2 & 2.70 & 2.25 & 9.02 & 0.19 & 14.16 \\
2017_3 & 2.99 & 2.37 & 9.30 & 0.14 & 14.80 \\
2017_4 & 3.69 & 3.02 & 12.99 & n.d. & 19.70 \\
2017_5 & 2.70 & 2.18 & 10.47 & n.d. & 15.35 \\
2017_6 & 2.82 & 2.37 & 9.78 & n.d. & 14.97 \\
2017_7 & 2.97 & 2.43 & 9.26 & 0.09 & 14.75 \\
2017_8 & 2.2 & 1.72 & 6.55 & 0.09 & 10.56 \\
2017_9 & 2.53 & 1.89 & 7.68 & 0.11 & 12.21 \\
2017_10 & 2.36 & 1.98 & 8.20 & 0.07 & 12.61 \\
2017_11 & 3.08 & 2.09 & 8.47 & 0.11 & 13.75 \\
2017_12 & 2.40 & 2.07 & 8.57 & 0.09 & 13.13 \\
\hline
\end{tabular}

n.d.: not detected.

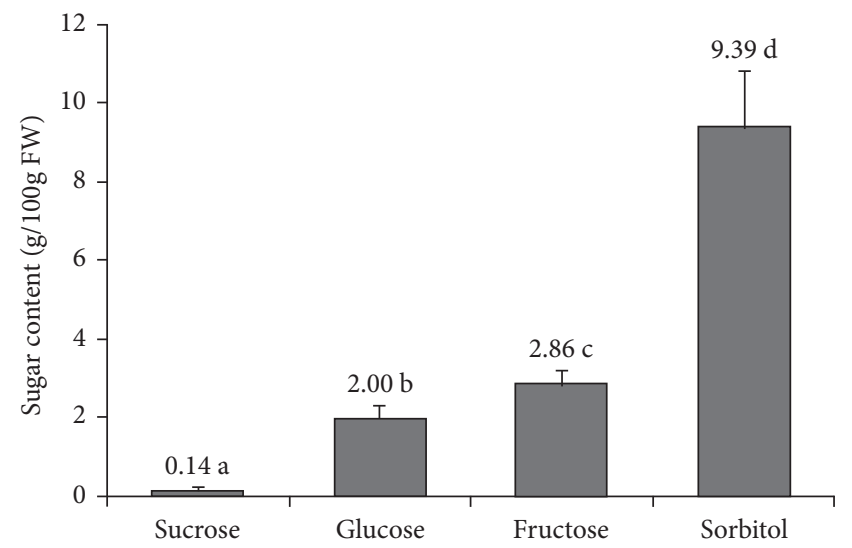

Figure 1: Average content (g/100 g FW) of sugars in 23 samples of black chokeberry fruits. Results are presented as mean values from all samples \pm SD. There are no significant differences among values marked with the same letters in individual groups.

fresh aronia berries [36-39]. All these studies reported that malic acid is the major representative of organic acids, but in our study, it was the predominant one only in 6 samples. In most of the cases, quinic acid was the major organic acid, reaching up to $591 \mathrm{mg} / 100 \mathrm{~g} \mathrm{FW}$.

The dominance of quinic acid is visible also from Figure 2 that presents the average data for the content of the investigated organic acids. The amount of ascorbic acid in the investigated samples varied between 37 and $92 \mathrm{mg} / 100 \mathrm{~g}$ FW with an average value of $65.2 \mathrm{mg} / 100 \mathrm{~g} \mathrm{FW}$. This is the third most abundant organic acid in aronia fruits, which makes fresh aronia berries a good source of vitamin C. Total amount of organic acids expressed as the sum of the individual representatives varies in the range $712.6-1028.9 \mathrm{mg} / 100 \mathrm{~g} \mathrm{FW}$.

\subsection{Polyphenol Content and Composition, and Antioxidant} Activity of Aronia Fruits. It is known from the literature that the total and individual polyphenol components in chokeberries vary significantly in their amounts [4]. This could be due to the used analytical protocols or various environmental (cultivar, habitat, fertilization, harvest time, climate, maturation, etc.) and genetic factors. In order to eliminate the influence of several of these factors, we used aronia fruits from the same cultivar "Nero," in the stage of full maturity (harvested in August). Nevertheless, there were significant differences in both the content and the composition of the individual phenolic representatives. The content of total polyphenolic compounds and their composition in fresh aronia berries are presented in Table 3. As it can be seen from the table, chokeberries are particularly rich source of proanthocyanidins, anthocyanins, and hydroxycinnamic acids. The total polyphenol content of the investigated samples varied between $1022 \mathrm{mg} / 100 \mathrm{~g}$ FW and $1795 \mathrm{mg} / 100 \mathrm{~g}$ FW, which differs more than $75 \%$. These findings are in agreement with the available information from other studies reporting polyphenol content of fresh berries in the range $690-2556 \mathrm{mg} / 100 \mathrm{~g} \mathrm{FW}$ [9]. The total content of proanthocyanidins in our study was in the range $522-1002 \mathrm{mg} / 100 \mathrm{~g}$ FW, which makes them the most abundant polyphenols in aronia berries. According to the literature data, proanthocyanidins in fresh aronia berries consist of epicatechin units, and their content varies between 664 and $2120 \mathrm{mg} / 100 \mathrm{~g}$ [40]. Hellström et al. reported that different aronia varieties contain between $80 \%$ and 95\% extractable proanthocyanidins, and oligomers larger than 10-mers represent between 97 and $99.5 \%$ of the extractable proanthocyanidins [13]. The total amount of anthocyanins in the investigated berries varied more than 2.4-fold between samples with the lowest and the highest anthocyanin content. The results in our study $(284-686 \mathrm{mg} / 100 \mathrm{~g}$ fresh weight) are in agreement with other studies reporting anthocyanin content in fresh berries as $428 \mathrm{mg} / 100 \mathrm{~g}$ [41], $434 \mathrm{mg} / 100 \mathrm{~g}$ [26], and $461 \mathrm{mg} / 100 \mathrm{~g}$ [42]. From the literature, it is known that aronia anthocyanin profile consist exclusively of cyanidin glycosides, and cyanidin-3galactoside and cyanidin-3-arabinoside are the major representatives with more than $90 \%$ of the available anthocyanins in fresh aronia berries [43]. The cumulative amount of hydroxycinnamic acids in the investigated berries was almost equal to that of the anthocyanins, making them the third most abundant phenolic class in Aronia melanocarpa. The highest content of chlorogenic acid ( $187.9 \mathrm{mg} / 100 \mathrm{~g} \mathrm{FW}$ ) was found in sample 2017_4 and is in agreement with other studies [25]. Interestingly, the highest quantity of neochlorogenic acid in our study $(214.5 \mathrm{mg} / 100 \mathrm{~g} \mathrm{FW})$ found in sample 2017_8 exceeds significantly the available results in the literature - 84-117 mg/100 g FW [25], $123 \mathrm{mg} / 100 \mathrm{~g} \mathrm{FW}$ [27], and $59-79 \mathrm{mg} / 100 \mathrm{~g} \mathrm{FW}$ [44]. As it is evident from Table 3, quercetin glycosides (flavonols) and epicatechin (flavan-3-ol) are also present in the berries. The content of 
TABLE 2: Organic acid content (mg/100 g FW) in 23 samples of aronia berries.

\begin{tabular}{|c|c|c|c|c|c|c|c|c|}
\hline & Quinic acid & Malic acid & Ascorbic acid & Shikimic acid & Citric acid & Oxalic acid & Succinic acid & Total \\
\hline 2016_1 & 473.8 & 338.5 & 65.1 & 7.9 & 32.0 & 4.0 & 4.8 & 926.1 \\
\hline 2016_2 & 462.2 & 324.5 & 87.2 & 10.9 & 38.1 & 3.2 & 4.3 & 930.4 \\
\hline 2016_3 & 460.9 & 341.2 & 91.8 & 13.7 & 34.7 & 3.1 & 4.9 & 950.3 \\
\hline 2016_4 & 293.4 & 343.9 & 47.7 & 5.8 & 30.0 & 3.1 & 23.8 & 747.7 \\
\hline $2016 \_5$ & 434.6 & 313.3 & 83.1 & 10.5 & 39.1 & 3.3 & 2.8 & 886.7 \\
\hline 2016_6 & 377.4 & 316.6 & 50.0 & 5.3 & 39.9 & 3.7 & 14.1 & 807.0 \\
\hline 2016_7 & 311.4 & 380.2 & 37.3 & 6.6 & 35.0 & 3.1 & 3.0 & 776.6 \\
\hline $2016 \_8$ & 375.2 & 385.8 & 56.2 & 10.9 & 30.9 & 3.0 & 1.9 & 863.9 \\
\hline 2016_9 & 441.2 & 312.4 & 62.3 & 11.6 & 28.8 & 2.8 & 3.6 & 862.7 \\
\hline 2016_10 & 335.9 & 426.8 & 50.9 & 5.7 & 32.6 & 3.8 & 10.4 & 866.1 \\
\hline 2016_11 & 334.2 & 368.7 & 65.3 & 7.2 & 27.5 & 2.6 & 4.3 & 809.8 \\
\hline 2017_1 & 432.9 & 297.7 & 39.8 & 10.7 & 29.8 & 3.6 & 6.9 & 821.4 \\
\hline $2017 \_2$ & 330.5 & 310.0 & 41.4 & 9.4 & 28.0 & 3.3 & 6.6 & 729.2 \\
\hline 2017_3 & 420.4 & 335.7 & 66.6 & 16.4 & 35.3 & 3.2 & 3.8 & 881.4 \\
\hline 2017_4 & 467.5 & 303.1 & 54.2 & 11.5 & 40.8 & 4.2 & 5.5 & 886.8 \\
\hline 2017_5 & 591.0 & 320.7 & 64.9 & 17.5 & 27.4 & 3.6 & 3.8 & 1028.9 \\
\hline 2017_6 & 391.3 & 266.2 & 79.1 & 6.6 & 23.4 & 2.9 & 4.0 & 773.5 \\
\hline 2017_7 & 415.2 & 435.5 & 85.1 & 6.1 & 37.1 & 3.3 & 3.7 & 985.9 \\
\hline 2017_8 & 232.4 & 392.2 & 57.7 & 4.8 & 18.3 & 2.4 & 4.7 & 712.5 \\
\hline 2017_9 & 366.0 & 236.4 & 73.0 & 5.4 & 41.3 & 3.4 & 9.5 & 735.0 \\
\hline 2017_10 & 400.5 & 229.5 & 69.8 & 5.1 & 34.9 & 2.5 & 9.3 & 751.6 \\
\hline 2017_11 & 553.2 & 273.5 & 91.3 & 7.4 & 29.9 & 5.4 & 21.7 & 982.4 \\
\hline 2017_12 & 399.3 & 294.6 & 80.7 & 6.8 & 26.4 & 2.9 & 7.0 & 817.7 \\
\hline
\end{tabular}

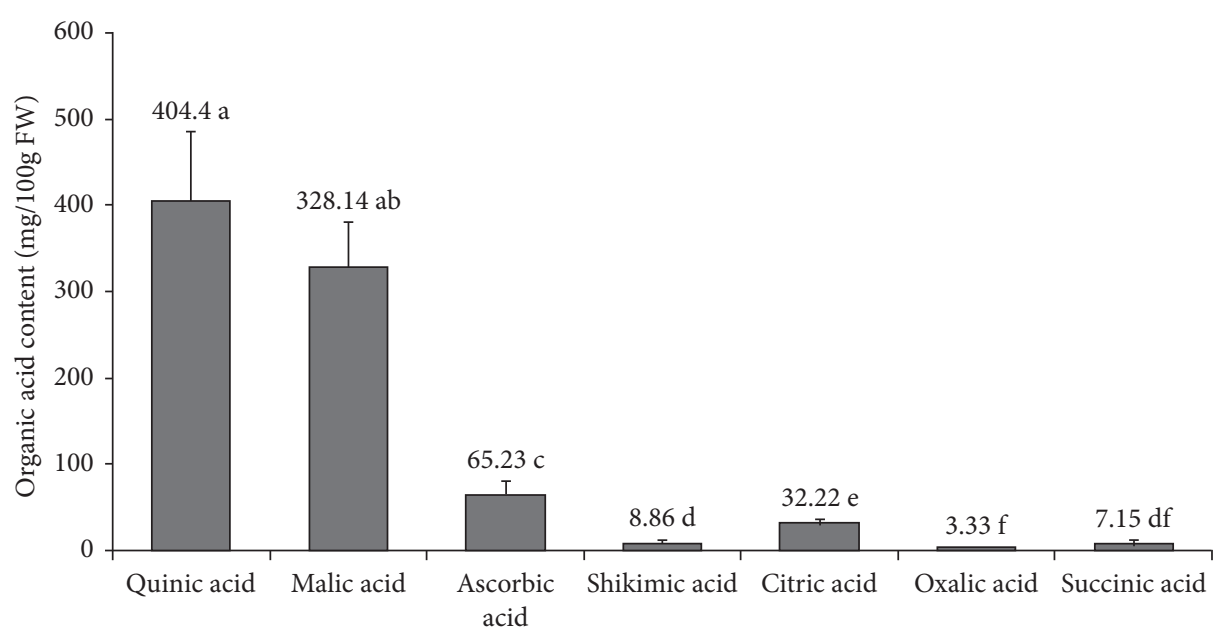

Figure 2: Average content (mg/100 g FW) of organic acids in 23 samples of black chokeberry fruits. Results are presented as mean values from all samples \pm SD. There are no significant differences among values marked with the same letters in individual groups.

epicatechin is the most significant, reaching up to $124 \mathrm{mg} / 100 \mathrm{~g}$ FW, which is higher than the available literature data [25]. The content of quercetin glycosides (rutinoside and glucoside) is several times higher than that of the aglycon itself.

It is well known that polyphenolic compounds are the main substances, responsible for the antioxidant activity of plant materials, and there is a good correlation between their content and antioxidant properties of plant foods [5]. Given the fact that polyphenol content and composition of the investigated samples differed significantly, it could be expected that there will be differences in the antioxidant activity, as well. There are few studies reporting ORAC values for chokeberries $158 \mu \mathrm{mol} \mathrm{TE} / \mathrm{g}$ FW [40] and $160.2 \mu \mathrm{mol}$
TE/g FW [41]. From the current study, it could be seen that antioxidant activity of fresh chokeberries varies in very broad range from $109 \mu \mathrm{mol} \mathrm{TE} / \mathrm{g}$ FW to $191 \mu \mathrm{mol} \mathrm{TE} / \mathrm{g}$ FW (Table 3).

The detailed analysis of the chemical composition of 23 aronia samples cultivated in Bulgaria revealed significant variations in the content of different primary (sugars and organic acids) and secondary (phenolic compounds) metabolites. It is known that warm climate, characteristic for Bulgaria could favour the accumulation of sugars in fruits and vegetables. This could be the reason for the higher sorbitol content in Bulgarian chokeberries in comparison to previous studies. From the other hand, it is known that different chokeberry cultivars differ significantly in their 


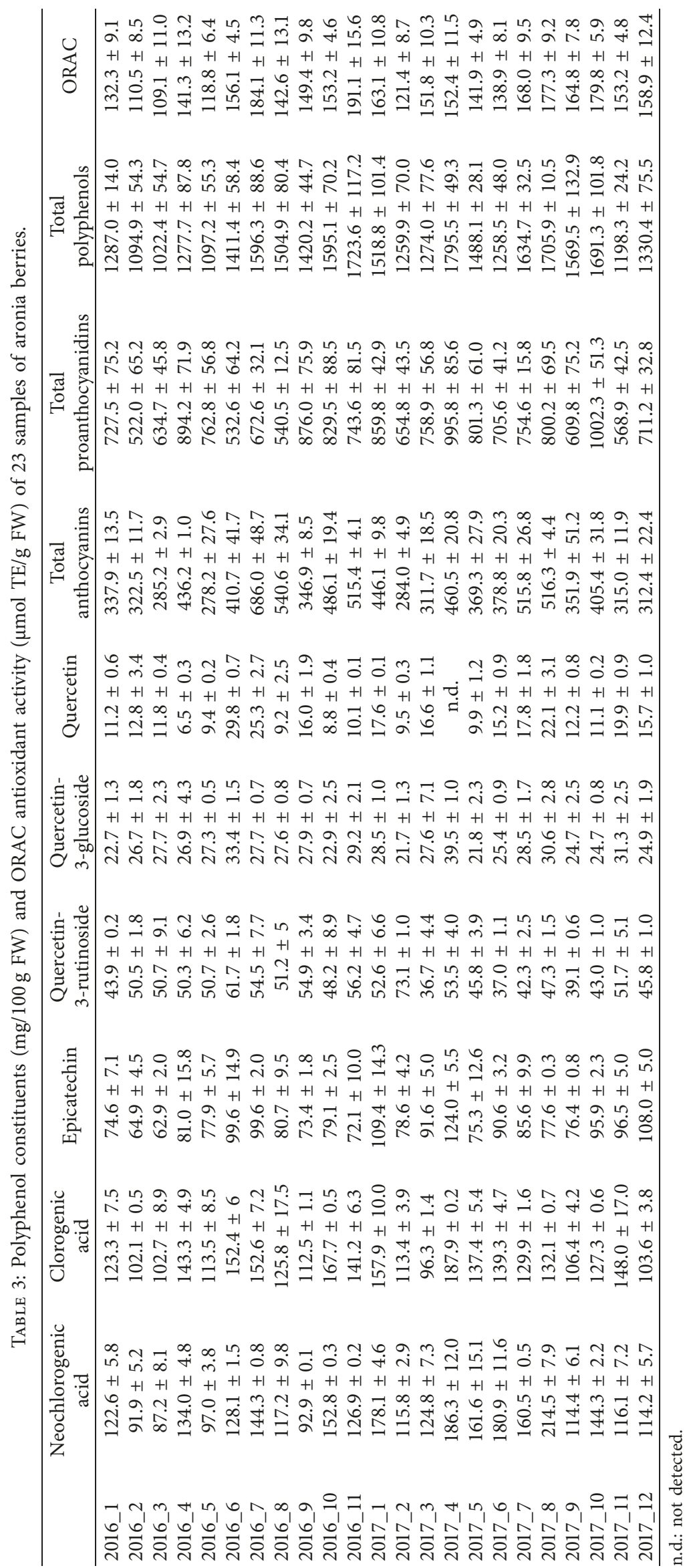


polyphenol content [28]. In our study, chokeberries even from the same variety differed significantly in their polyphenol content and composition. This shows that not the cultivar, but the agrotechnique and/or microclimate features, specific for the different regions, are more determining for the accumulation of phenolic compounds in chokeberries. This is very interesting and important since variations in the chemical composition of aronia fruits, particularly in their polyphenol content and composition, are prerequisite for different biological activity. However, future in vivo studies should be performed to check this hypothesis.

\subsection{Chemical Composition and Antioxidant Activity of Aronia} Functional Drinks. Due to the antioxidant activity and multiple health benefits of aronia berries, their products could be referred as functional foods. A food can be called functional if it impacts one or more functions of the body related to improving health or reducing the risk of illness [45]. Health Canada defines functional foods as being "similar in appearance to, or maybe, a conventional food that is consumed as part of a usual diet, and is demonstrated to have physiological benefits and reduce the risk of chronic disease beyond basic nutritional functions" [46]. The European Commission Concerted Action on Functional Food Science in Europe considers foods to be functional if they have a beneficial effect on one or more functions of the body and are still in the form of food, not a dietary supplement [47]. However, European Union has strict regulations about the requirements towards all fruit-based drinks, including fruit juices and fruit nectars described in Council Directive 2001/112/EC [48], amended by Directive 2012/12/EU [49]. According to the later Directive, fruit juice is "the fermentable but unfermented product obtained from the edible part of fruit which is sound and ripe, fresh or preserved by chilling or freezing of one or more kinds mixed together having the characteristic colour, flavour and taste typical of the juice of the fruit from which it comes." According to the same regulation, fruit nectar is "the fermentable but unfermented product which is obtained by adding water with or without the addition of sugars and/or honey to fruit juice, to fruit purée and/or to concentrated fruit purée and/or to a mixture of those products." In our study, we decided to prepare both types of functional foods from aronia and to investigate their chemical composition. As already demonstrated, chemical composition of fresh aronia berries differs significantly, which is a prerequisite for variations in the functionality of aronia functional drinks. Another factor that could also affect this feature is the technological processing. Since juices are produced only by fruits, without any food additives (sweeteners, acids, acidity regulators, etc.), we investigated the possibility to change aronia fruit juice composition by only changing the treating temperature of the fruit mash. For that purpose, we treated homogenized aronia fruits for 1 hour at $20^{\circ} \mathrm{C}, 40^{\circ} \mathrm{C}, 60^{\circ} \mathrm{C}$, or $80^{\circ} \mathrm{C}$, followed by pressing and filtering aronia juice. The obtained juices were denoted as aronia juice (AJ)20, AJ40, AJ60, and AJ80, respectively. We used the same temperatures for the preparation of aronia nectars standardized to $40 \%$ fruit content, denoted as aronia nectars (AN)20, AN40, AN60, and AN80, respectively. The only difference was the addition of water to fruit mash, which served as an extragent for chokeberry phenolics. We used the content of total polyphenols and anthocyanins in the obtained juices and nectars as criteria for the efficiency of the extraction process. As it could be seen from Figure 3, the temperature had profound effect on the extraction of anthocyanins and polyphenols from fresh aronia berries.

From Figure 3(a), it is evident that juice extracted at $20^{\circ} \mathrm{C}$ contains $1030 \mathrm{mg} / \mathrm{L}$ and $6080 \mathrm{mg} / \mathrm{L}$ anthocyanins and polyphenols, respectively. Increasing the extraction temperature to $80^{\circ} \mathrm{C}$ lead to a gradual increase in both anthocyanin and polyphenol contents of the obtained juices. In the case of anthocyanins, the difference was more than $127 \%$, whereas for polyphenols, the increment between the lowest and the highest temperature was $68 \%$. Although the value of anthocyanins at $80^{\circ} \mathrm{C}$ was the highest, it was not significantly different from that for AJ60. In the case of polyphenols, results at all temperatures were significantly different, indicating that fruit juice was enriched to other nonanthocyanin phenolics. Degustation of the juices showed that AJ80 was considerably more astringent and unpleasant than juices obtained at lower temperatures, indicating that AJ80 was the richest one in condensed tannins. The trend in the influence of temperature on nectar extraction was slightly different (Figure 3(b)). Although there was increment in both anthocyanin and polyphenol contents between $20^{\circ} \mathrm{C}$ and $40^{\circ} \mathrm{C}$, the differences were not significant. The biggest jump in both parameters occurred in the heating step between $40^{\circ} \mathrm{C}$ and $60^{\circ} \mathrm{C}$. Similarly, to juice extraction, the polyphenol content was the highest at AN80, whereas there was no significant difference in anthocyanin content between AN60 and AN80. In order to obtain more detailed information about the chemical composition of juice and nectars, we analyzed the major polyphenols and anthocyanins in them, and the results are shown in Table 4. From the results, it could be concluded that all classes of phenolic compounds (anthocyanins, hydroxycinnamic acids, flavan3-ols, and flavonols) present in aronia berries increase their content in both juices and nectars with the elevation of processing temperature. It is known that anthocyanins have different therapeutic effects and are partly responsible for the biological activities and functionality of aronia berries. Furthermore, because of their beautiful ruby red colour, they are also important for the sensory perception of the resulting chokeberry juices and nectars. Therefore, their high content in fruits and aronia foods and drinks is extremely desirable. Chokeberry proanthocyanidins are homogeneous [50], and due to their polymeric structure, they are not absorbed by human organism. It is believed that they pass unchanged through the gastrointestinal tract and are subjected to degradation by the colon microflora. This yields a variety of metabolites, mainly phenolic acids, with antioxidant activity $[51,52]$. Nevertheless, through their strong antioxidant activity, proanthocyanidins play an important protective role in the gastrointestinal tract. We note that despite their high antioxidant activity, proanthocyanidins 


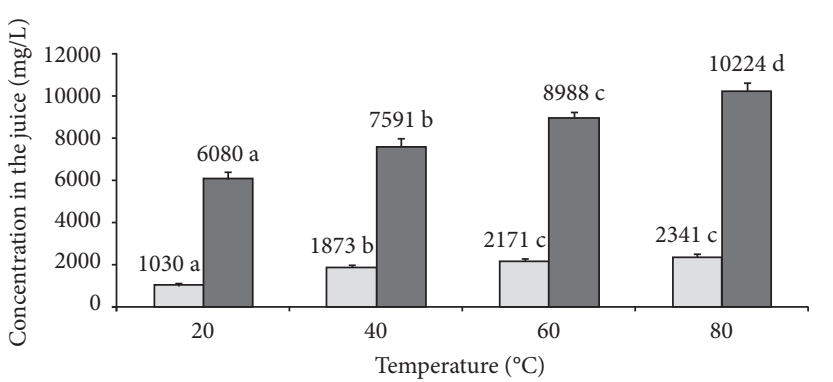

- Anthocyanins, mg/L

- Polyphenols, mg/L

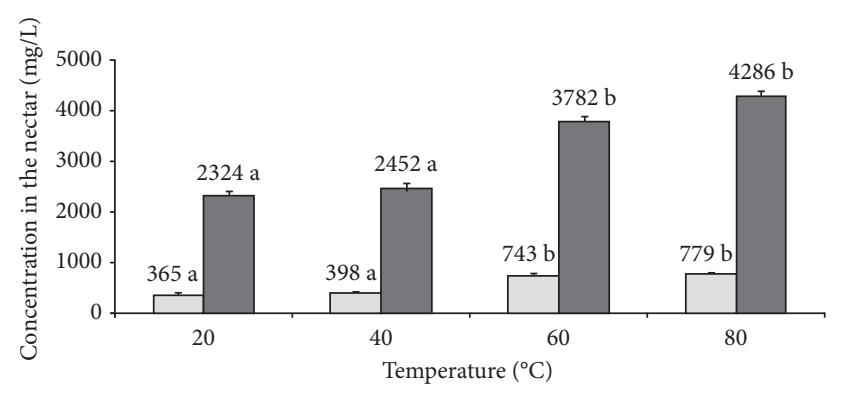

a Anthocyanins, mg/L

- Polyphenols, mg/L

(a)

(b)

FIGURE 3: Influence of treatment temperature on polyphenol and anthocyanin content of aronia fruit juices (a) and fruit nectars (b). Results are presented as mean values from all samples \pm SD. There are no significant differences among values marked with the same letters in individual groups.

TAвLe 4: Polyphenol content (mg/l) and composition of aronia fruit juices and nectars obtained at different temperatures.

\begin{tabular}{|c|c|c|c|c|c|c|c|c|c|c|}
\hline & \multirow{2}{*}{$\begin{array}{l}\text { Neochlorogenic } \\
\text { acid }\end{array}$} & \multirow{2}{*}{$\begin{array}{l}\text { Chlorogenic } \\
\text { acid }\end{array}$} & \multirow{2}{*}{ Epicatechin } & \multirow{2}{*}{$\begin{array}{l}\text { Quercetin- } \\
\text { 3-rutinoside }\end{array}$} & \multirow{2}{*}{$\begin{array}{l}\text { Quercetin- } \\
\text { 3-glucoside }\end{array}$} & \multirow{2}{*}{ Quercetin } & \multicolumn{4}{|c|}{ Anthocyanins } \\
\hline & & & & & & & Cy-3-Gal & Cy-3-Glc & Cy-3-Ara & Cy-3-Xyl \\
\hline AJ20 & 1066.4 & 889.8 & 196.4 & 155.7 & 115.9 & 68.1 & 874.9 & 54.4 & 247.7 & 4.8 \\
\hline AJ40 & 1421.6 & 1178.7 & 342.2 & 394.1 & 266.7 & 74.6 & 1418.2 & 102.3 & 412.9 & 9.3 \\
\hline AJ60 & 1633.5 & 1203.3 & 441.8 & 557.1 & 337.6 & 78.9 & 1867.3 & 133.1 & 571.1 & 12.3 \\
\hline AJ80 & 1720.8 & 1392.5 & 494.2 & 628.5 & 367.3 & 82.0 & 1940.0 & 135.1 & 586.1 & 12.5 \\
\hline AN20 & 486.4 & 397.7 & 88.2 & 100.2 & 84.9 & 12.4 & 596.3 & 39.9 & 157.5 & 3.2 \\
\hline AN40 & 506.8 & 427.9 & 113.3 & 115.0 & 89.2 & 18.2 & 705.1 & 50.9 & 198.1 & 3.4 \\
\hline AN60 & 531.8 & 448.5 & 139.6 & 210.3 & 152.5 & 22.6 & 852.1 & 60.6 & 253.0 & 5.3 \\
\hline AN80 & 603.3 & 475.4 & 147.4 & 217.3 & 161.7 & 25.4 & 862.4 & 60.8 & 253.6 & 5.3 \\
\hline
\end{tabular}

Cy: cyanidin; Gal: galactose; Glc: glucose; Ara: arabinose; Xyl: xylose.

possess astringent taste, which is a prerequisite for worsening the taste of fruits and products derived from them. Therefore, a balance between the content of proanthocynidins in aronia products and their palatability should be sought.

A recent study investigated the influence of juice processing factors on the quality of black chokeberry pomace as resource for anthocyanin colourants. Authors found that mashing led to a significant increment in the content of anthocyanins in all the processing treatments as compared to the frozen berries. Anthocyanin content in pomace was affected most strongly by enzyme treatment followed by maceration temperature. The preheating of the mash increased the juice yield and retention of anthocyanins in the pomace, whereas cold maceration without enzyme addition gave the highest concentrations of anthocyanins in the pomace [53]. It is well known that temperature could significantly affect extraction of polyphenols and anthocyanins from plant matter. For chokeberry, this was demonstrated by ultrasound-assisted extraction of polyphenols and anthocyanins from dried chokeberries and aronia wastes [54, 55]. These studies demonstrated the positive influence of the temperature on the extraction of polyphenols from aronia. For example, at $60^{\circ} \mathrm{C}$, the yield of extracted polyphenols from dried berries was approximately 3-fold higher, compared to the yields at $20^{\circ} \mathrm{C}$. This is due to the elevated solubility of polyphenols in the solvent, higher diffusivities, and the improved mass transfer at higher temperatures. However, these studies aimed the preparative extraction of anthocyanins and polyphenols, either from dried chokeberries or from aronia wastes. In our study, we investigated the effect of temperature in the preparation of ready-toconsume functional foods-juices and nectars. To our knowledge, the obtained results are the first evidence that functional foods from aronia could be enriched in polyphenols and particularly anthocyanins just by variation of temperature during technological processing. This is another prerequisite for obtaining aronia-based functional drinks with variable chemical composition and, therefore, different biological activity, even from the same batch of aronia fruits.

In Section 3.2 of our study, we hypothesized that the differences of the chemical composition of fresh aronia berries are prerequisite for different composition of aronia functional foods. Therefore, we decided to check that hypothesis by preparing functional foods-juices and nectars from aronia berries that differ in their chemical composition. Based on the results for polyphenol content and constituents of the investigated 23 samples aronia presented in Table 1, we have chosen 3 different batches of aronia with different polyphenol content, that were used for production of fruit juices and nectars. It is known that anthocyanins are temperature sensitive, and their exposure to high temperatures and prolonged heating have been reported to have a strong negative influence on their stability [56]. On the other hand, 
TABLE 5: Polyphenol content (mg/l) composition and antioxidant activity of aronia fruit juices and nectars obtained from different batches of aronia berries at $60^{\circ} \mathrm{C}$.

\begin{tabular}{|c|c|c|c|c|c|c|c|c|c|}
\hline & $\begin{array}{l}\text { Neochlorogenic } \\
\text { acid }\end{array}$ & $\begin{array}{l}\text { Chlorogenic } \\
\text { acid }\end{array}$ & Epicatechin & $\begin{array}{l}\text { Quercetin- } \\
\text { 3-rutinoside }\end{array}$ & $\begin{array}{l}\text { Quercetin- } \\
\text { 3-glucoside }\end{array}$ & Quercetin & $\begin{array}{c}\text { Total } \\
\text { anthocyanins }\end{array}$ & $\begin{array}{c}\text { Total } \\
\text { polyphenols }\end{array}$ & $\begin{array}{c}\text { ORAC, } \\
\mu \mathrm{mol} \mathrm{TE} / \mathrm{l}\end{array}$ \\
\hline \multicolumn{10}{|l|}{ Juices } \\
\hline $2016 \_3$ & 842.8 & 838.7 & 360.6 & 594.5 & 277.6 & 35.2 & 1040.3 & 5138.0 & 56542.3 \\
\hline 2016_11 & 873.6 & 1220.9 & 454.2 & 581.0 & 307.6 & 30.4 & 2236.0 & 7736.5 & 82564.6 \\
\hline $2017 \_8$ & 1633.5 & 1203.3 & 441.8 & 557.1 & 337.6 & 78.9 & 2171.9 & 8988.3 & 92654.8 \\
\hline \multicolumn{10}{|l|}{ Nectars } \\
\hline $2016 \_3$ & 327.7 & 327.4 & 181.3 & 196.8 & 70.0 & 16.1 & 571.1 & 2475.2 & 27562.3 \\
\hline 2016_11 & 461.6 & 454.0 & 230.6 & 232.8 & 80.0 & 18.5 & 1107.1 & 3286.7 & 36897.5 \\
\hline $2017 \_8$ & 531.8 & 448.5 & 239.6 & 210.3 & 152.5 & 22.6 & 743.1 & 3782.1 & 39254.4 \\
\hline
\end{tabular}

we revealed that heating from $60^{\circ} \mathrm{C}$ to $80^{\circ} \mathrm{C}$ does not result in significant elevation of anthocyanin content. Therefore, we decided to obtain fruit juices and fruit nectars at $60^{\circ} \mathrm{C}$. The results for the chemical composition and antioxidant activity of the obtained functional drinks are presented in Table 5.

The results from these experiments support our hypothesis and revealed that indeed the differences in chemical composition of aronia berries result in functional foods that differ significantly in their chemical composition and antioxidant activity. For example, juice obtained from sample 2017_8 had twice the content of anthocyanins of juice 2017_3, 75\% more polyphenols, and revealed almost $64 \%$ higher antioxidant activity. As already stated, this is a prerequisite for altered biological activity of aronia functional foods that should be investigated in further studies.

\section{Conclusion}

The current study presents comprehensive data on the chemical composition of 23 aronia berries grown under the climatic conditions of Bulgaria. We demonstrated that chokeberry samples differ significantly in both the content and the composition of organic acids, sugars, and phenolic compounds. In several cases, these differences were more than $100 \%$. Additionally, we demonstrated that temperature of juice pressing and nectar extraction has a profound effect on the polyphenol content and composition of these products. We revealed that the differences in the chemical composition of aronia berries and the technological processing parameters could result in functional foods (juices and nectars) that differ significantly in their chemical composition and antioxidant activity, which is a prerequisite for altered biological activity. However, future in vivo studies should be performed to check this hypothesis.

\section{Data Availability}

The data used to support the findings of this study are included within the article.

\section{Conflicts of Interest}

The authors declare that there are no conflicts of interest regarding the publication of this paper.

\section{Acknowledgments}

This work was funded by the Bulgarian National Science Fund (Grant No. DN09/20-21.12.2016).

\section{References}

[1] I. Ellingsen, E. Hjerkinn, I. Seljeflot, H. Arnesen, and S. Tonstad, "Consumption of fruit and berries is inversely associated with carotid atherosclerosis in elderly men," British Journal of Nutrition, vol. 99, no. 3, pp. 674-681, 2008.

[2] M. G. Miller and B. Shukitt-Hale, "Berry fruit enhances beneficial signaling in the brain," Journal of Agricultural and Food Chemistry, vol. 60, no. 23, pp. 5709-5715, 2012.

[3] T. Tsuda, "Dietary anthocyanin-rich plants: biochemical basis and recent progress in health benefits studies," Molecular Nutrition \& Food Research, vol. 56, no. 1, pp. 159-170, 2012.

[4] P. N. Denev, C. G. Kratchanov, M. Ciz, A. Lojek, and M. Kratchanova, "Bioavailability and antioxidant activity of black chokeberry (Aronia melanocarpa) polyphenols: in vitro and in vivo evidences and possible mechanisms of action: a review," Comprehensive Reviews in Food Science and Food Safety, vol. 11, no. 5, pp. 471-489, 2012.

[5] P. Denev, A. Lojek, M. Ciz, and M. Kratchanova, "Antioxidant activity and polyphenol content of Bulgarian fruits," Bulgarian Journal of Agricultural Science, vol. 19, no. 1, pp. 22-27, 2013.

[6] J. W. Hardin, "The enigmatic chokeberries (Aronia, Rosaceae)," Bulletin of the Torrey Botanical Club, vol. 100, no. 3, pp. 178-184, 1973.

[7] J. Seidemann, "Chokeberries a fruit little-known till now," Deutsche Lebensmittel-Rundschau, vol. 89, pp. 149-151, 1993.

[8] AW. Strigl, E. Leitner, and W. Pfannhauser, "Die schwarze Apfelbeere (Aronia melanocarpa) als naturliche farbstoffquelle," Deutsche Lebensmittel-Rundschau, vol. 91, pp. 177-180, 1995.

[9] SE. Kulling and H. M. Rawel, "Chokeberry (Aronia melanocarpa) - a review on the characteristic components and potential health effects," Planta Medica, vol. 74, no. 13, pp. 1625-1634, 2008.

[10] C. Chrubasik, G. Li, and S. Chrubasik, "The clinical effectiveness of chokeberry: a systematic review," Phytotherapy Research, vol. 24, pp. 1107-1114, 2010.

[11] S. Borowska and M. Brzoska, "Chokeberries (Aronia melanocarpa) and their products as a possible means for the prevention and treatment of noncommunicable diseases and unfavorable health effects due to exposure to xenobiotics," Comprehensive Reviews in Food Science and Food Safety, vol. 15, no. 6, pp. 982-1017, 2016. 
[12] Y. M. Park and J. B. Park, "The preventive and therapeutic effects of aronox extract on metabolic abnormality and hypertension," Journal of the Korean Society of Hypertension, vol. 17, no. 3, pp. 95-102, 2011.

[13] J. K. Hellström, A. R. Torronen, and P. H. Mattila, "Proanthocyanidins in common food products of plant origin," Journal of Agricultural and Food Chemistry, vol. 57, no. 17, pp. 7899-7906, 2009.

[14] S. Valcheva-Kuzmanova, K. Kuzmanov, S. Tsanova-Savova et al., "Lipid-lowering effects of Aronia melanocarpa fruit juice in rats fed cholesterol-containing diets," Journal of Food Biochemistry, vol. 31, no. 5, pp. 589-602, 2007.

[15] S. Valcheva-Kuzmanova, K. Marazova, I. Krasnaliev, B. Galunska, P. Borisova, and A. Belcheva, "Effect of Aronia melanocarpa fruit juice on indomethacin-induced gastric mucosal damage and oxidative stress in rats," Experimental and Toxicologic Pathology, vol. 56, no. 6, pp. 385-392, 2005.

[16] S. Valcheva-Kuzmanova, P. Borisova, B. Galunska, I. Krasnaliev, and A. Belcheva, "Hepatoprotective effect of the natural fruit juice from Aronia melanocarpa on carbon tetrachloride-induced acute liver damage in rats," Experimental and Toxicologic Pathology, vol. 56, no. 3, pp. 195-201, 2004.

[17] V. Krajka-Kuzniak, H. Szaefer, E. Ignatowicz, T. Adamska, J. Oszmia'nski, and W. Baer-Dubowska, "Effect of chokeberry (Aronia melanocarpa) juice on the metabolic activation and detoxication of carcinogenic $N$-nitrosodiethylamine in rat liver," Journal of Agricultural and Food Chemistry, vol. 57, no. 11, pp. 5071-5077, 2009.

[18] R. Balansky, G. Ganchev, M. Iltcheva et al., "Inhibition of lung tumor development by berry extracts in mice exposed to cigarette smoke," International Journal of Cancer, vol. 131, no. 9, pp. 1991-1997, 2012.

[19] M. P. Yaneva, A. D. Botushanova, L. A. Grigorov, J. L. Kokov, E. P. Todorova, and M. G. Krachanova, "Evaluation of the immunomodulatory activity of aronia in combination with apple pectin in patients with breast cancer undergoing postoperative radiation therapy," Folia Medica, vol. 44, no. 12, pp. 22-25, 2002

[20] S. Park, JI. Kim, I. Lee et al., "Aronia melanocarpa and its components demonstrate antiviral activity against influenza viruses," Biochemical and Biophysical Research Communications, vol. 440, no. 1, pp. 14-19, 2013.

[21] E. Daskalova, S. Delchev, Y. Peeva et al., "Antiatherogenic and cardioprotective effects of black chokeberry (Aronia melanocarpa) juice in ageing rats," Evidence-Based Complementary and Alternative Medicine, vol. 2015, Article ID 717439, 10 pages, 2015.

[22] M. Brzóska, J. Rogalska, M. Galazyn-Sidorczuk, M. Jurczuk, A. Roszczenko, and M. Tomczyk, "Protective effect of Aronia melanocarpa polyphenols against cadmium-induced disorders in bone metabolism: a study in a rat model of lifetime human exposure to this heavy metal," Chemico-Biological Interactions, vol. 229, pp. 132-146, 2015.

[23] BM. Loo, I. Erlund, R. Koli et al., "Consumption of chokeberry (Aronia mitschurinii) products modestly lowered blood pressure and reduced low-grade inflammation in patients with mildly elevated blood pressure," Nutrition Research, vol. 36, no. 11, pp. 1222-1230, 2016.

[24] S. B. Simeonov, N. P. Botushanov, E. B. Karahanian, M. B. Pavlova, H. K. Husianitis, and D. M. Troev, "Effects of Aronia melanocarpa juice as part of the dietary regimen in patients with diabetes mellitus," Folia Medica, vol. 44, pp. 20-23, 2002.
[25] O. Rop, J. Mlcek, T. Jurikova et al., "Phenolic content, antioxidant capacity, radical oxygen species scavenging and lipid peroxidation inhibiting activities of extracts of five black chokeberry (Aronia melanocarpa (Michx.) Elliot) cultivars," Journal of Medicinal Plants Research, vol. 4, no. 22, pp. 2431-2437, 2010.

[26] L. Jakobek, M. Seruga, M. Medvedovic-Kosanovic, and I. Novak, "Antioxidant activity and polyphenols of aronia in comparison to other berry species," Agriculturae Conspectus Scientificus, vol. 72, no. 4, pp. 301-306, 2007.

[27] R. Slimestad, K. Torskangerpoll, H. S. Nateland, T. Johannessen, and N. H. Giske, "Flavonols from black chokeberries, Aronia melanocarpa," Journal of Food Composition and Analysis, vol. 18, no. 1, pp. 61-88, 2005.

[28] H. Wangensteen, M. Braunlich, V. Nikolic, K. Malterud, R. Slimestad, and H. Barsett, "Anthocyanins, proanthocyanidins and total phenolics in four cultivars of aronia: antioxidant and enzyme inhibitory effects," Journal of Functional Foods, vol. 7, pp. 746-752, 2014.

[29] A. Skoczynska, I. Jedrychowska, R. Poreba et al., "Influence of chokeberry juice on arterial blood pressure and lipid parameters in men with mild hypercholesterolemia," Pharmacological Reports, vol. 59, pp. 177-1782, 2007.

[30] P. Denev, M. Kratchanova, M. Ciz et al., "Biological activities of selected polyphenol-rich fruits related to immunity and gastrointestinal health," Food Chemistry, vol. 157, pp. 37-44, 2014.

[31] V. Singleton and J. Rossi, "Colorimetry of total phenolic with phosphomolybdic phosphotungstic acid reagents," American Journal of Enology and Viticulture, vol. 16, pp. 144-158, 1965.

[32] C. Sarneckis, R. G. Dambergs, P. Jones, M. Mercurio, M. J. Herderich, and P. Smith, "Quantification of condensed tannins by precipitation with methyl cellulose: development and validation of an optimised tool for grape and wine analysis," Australian Journal of Grape and Wine Research, vol. 12, no. 1, pp. 39-49, 2006.

[33] J. Lee, "Determination of total monomeric anthocyanin pigment content of fruits juices, beverages, natural colorants and wines by the $\mathrm{pH}$ differential method: collaborative study," Journal of AOAC International, vol. 88, no. 5, pp. 1269-1278, 2005.

[34] B. Ou, M. Hampsch-Woodill, and R. L. Prior, "Development and validation of an improved oxygen radical absorbance capacity assay using fluorescein as the fluorescence probe," Journal of Agricultural and Food Chemistry, vol. 49, no. 10, pp. 4619-4626, 2001.

[35] P. Denev, M. Ciz, G. Ambrozova, A. Lojek, I. Yanakieva, and M. Kratchanova, "Solid phase extraction of berries' anthocyanins and evaluation of their antioxidative properties," Food Chemistry, vol. 123, no. 4, pp. 1055-1061, 2010.

[36] V. Ara, "Schwarzfruchtige Aronia: Gesund-und bald, in aller Munde?," Fachzeitschrift Flüssiges Obst, vol. 10, pp. 653-658, 2002.

[37] J. Hofsommer and S. Koswig, "Zum nachweis von Aronia in schwarzer johannisbeere," Fachzeitschrift Flüssiges Obst, vol. 6, pp. 289-293, 2005.

[38] J. Šnebergrová, H. Č́ížková, E. Neradová, B. Kapci, A. Rajchl, and M. Voldřich, "Variability of characteristic components of aronia," Czech Journal of Food Sciences, vol. 32, no. 1, pp. 25-30, 2014.

[39] T. Tanaka and A. Tanaka, "Chemical components and characteristics of black chokeberry," Nippon Shokuhin Kagaku Kogaku Kaishi, vol. 48, no. 8, pp. 606-610, 2001. 
[40] XL. Wu, L. W. Gu, R. L. Prior, and S. McKay, "Characterization of anthocyanins and proanthocyanidins in some cultivars of Ribes, Aronia, and Sambucus and their antioxidant capacity," Journal of Agricultural and Food Chemistry, vol. 52, no. 26, pp. 7846-7856, 2004.

[41] W. Zheng and S. Y. Wang, "Oxygen radical absorbing capacity of phenolics in blueberries, cranberries, chokeberries, and lingonberries," Journal of Agricultural and Food Chemistry, vol. 51, pp. 502-509, 2003.

[42] S. Benvenuti, F. Pellati, M. Melegari, and D. Bertelli, "Polyphenols, anthocyanins, ascorbic acid, and radical scavenging activity of Rubus, Ribes and Aronia," Journal of Food Science, vol. 69, no. 3, pp. FCT164-FCT169, 2004.

[43] J. Oszmianski and A. Wojdylo, "Aronia melanocarpa phenolics and their antioxidant activity," European Food Research and Technology, vol. 221, no. 6, pp. 809-913, 2005.

[44] I. Ochmian, J. Grajkowski, and M. Smolik, "Comparison of some morphological features, quality and chemical content of four cultivars of chokeberry fruits (Aronia melanocarpa)," Notulae Botanicae Horti Agrobotanici Cluj-Napoca, vol. 40, no. 1, pp. 253-260, 2012.

[45] F. Shahidi, "Nutraceuticals and functional foods whole versus processed foods," Trends in Food Science and Technology, vol. 20, no. 9, pp. 376-387, 2009.

[46] http://www.hc-sc.gc.ca/.

[47] https://ec.europa.eu/jrc/en/publication/eur-scientific-andtechnical-research-reports/functional-food-european-union.

[48] Council Directive 2001/112/EC relating to fruit juices and certain similar products intended for human consumption from 20 December 2001.

[49] Directive 2012/12/eu of the European parliament and of the Council amending Council Directive 2001/112/EC relating to fruit juices and certain similar products intended for human consumption from 19 April 2012.

[50] J. C. Espin, M. T. Garcia-Conesa, and F. A. Tomas-Barberan, "Nutraceuticals: facts and fiction," Phytochemistry, vol. 68, no. 22-24, pp. 2986-3008, 2007.

[51] S. Deprez, I. Mila, J.-F. Huneau, D. Tom, and A. Scalbert, "Transport of proanthocyanidin dimer, trimer and polymer across monolayers of human intestinal epithelial Caco-2 cells," Antioxidants and Redox Signaling, vol. 3, no. 6, pp. 957-967, 2001.

[52] M. P. Gonthier, J. L. Donovan, O. Texier, C. Felgines, C. Remesy, and A. Scalbert, "Metabolism of dietary procyanidins in rats," Free Radical Biology and Medicine, vol. 35, no. 8, pp. 837-844, 2003.

[53] M. Vagiri and M. Jensen, "Influence of juice processing factors on quality of black chokeberry pomace as a future resource for colour extraction," Food Chemistry, vol. 217, no. 15, pp. 409-417, 2017.

[54] L. G. d'Alessandro, K. Kriaa, I. Nikov, and K. Dimitrov, "Ultrasound assisted extraction of polyphenols from black chokeberry," Separation and Purification Technology, vol. 93, pp. 42-47, 2012.

[55] L. G. d'Alessandro, K. Dimitrov, P. Vauchel, and I. Nikov, "Kinetics of ultrasound assisted extraction of anthocyanins from Aronia melanocarpa (black chokeberry) wastes," Chemical Engineering Research and Design, vol. 92, no. 10, pp. 1818-1826, 2014.

[56] A. Patras, N. P. Brunton, C. O’Donnell, and B. Tiwari, "Effect of thermal processing on anthocyanin stability in foods; mechanisms and kinetics of degradation," Trends in Food Science and Technology, vol. 21, no. 1, pp. 3-11, 2010. 

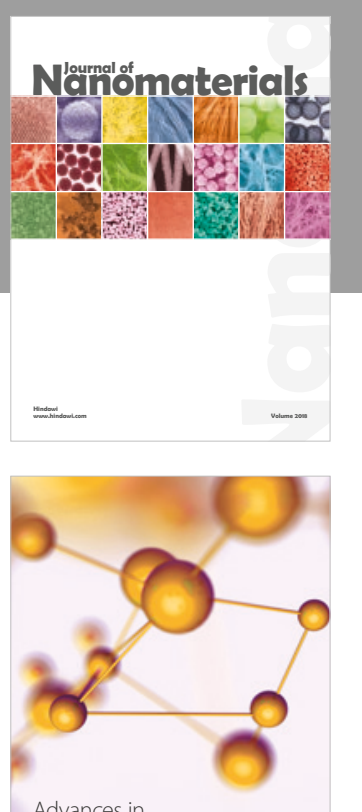

Physical Chemistry
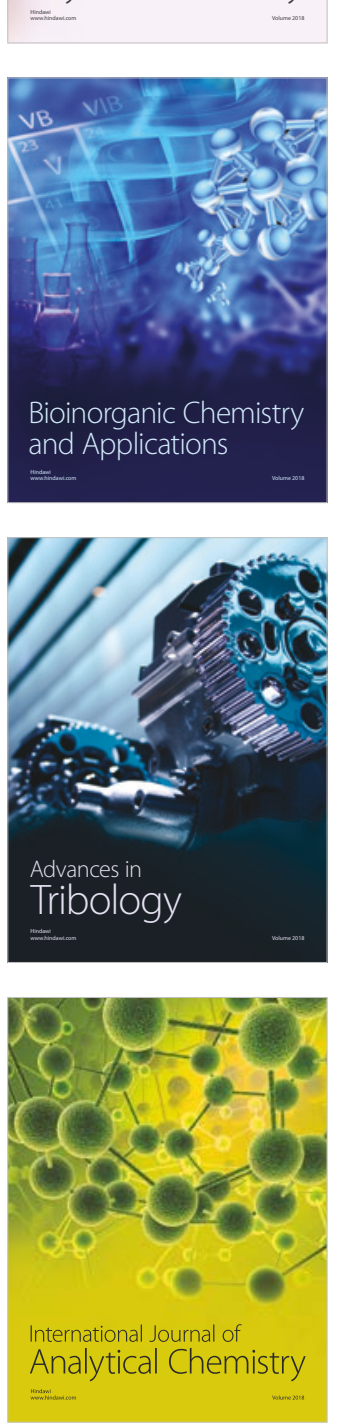

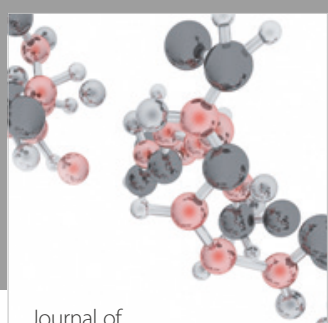

Analytical Methods

in Chemistry

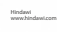

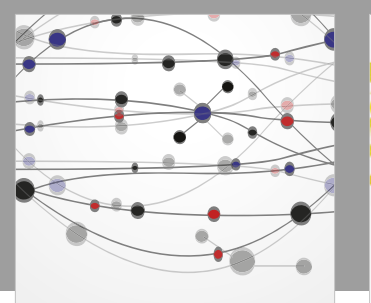

The Scientific World Journal

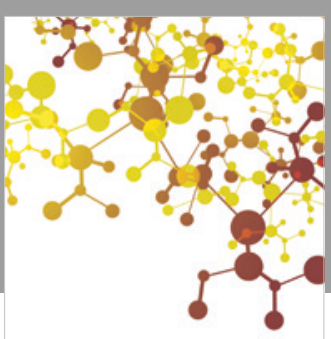

Journal of

Applied Chemistry
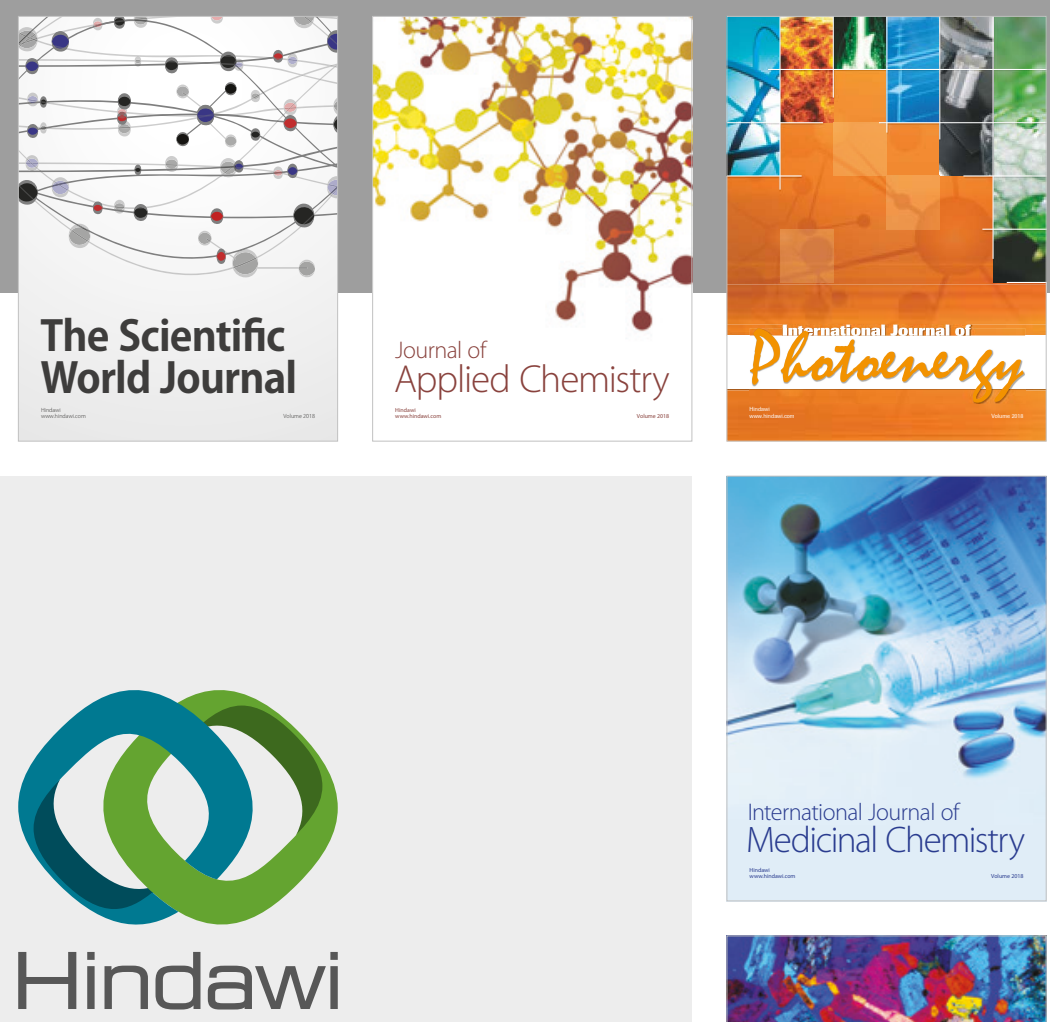

Submit your manuscripts at

www.hindawi.com
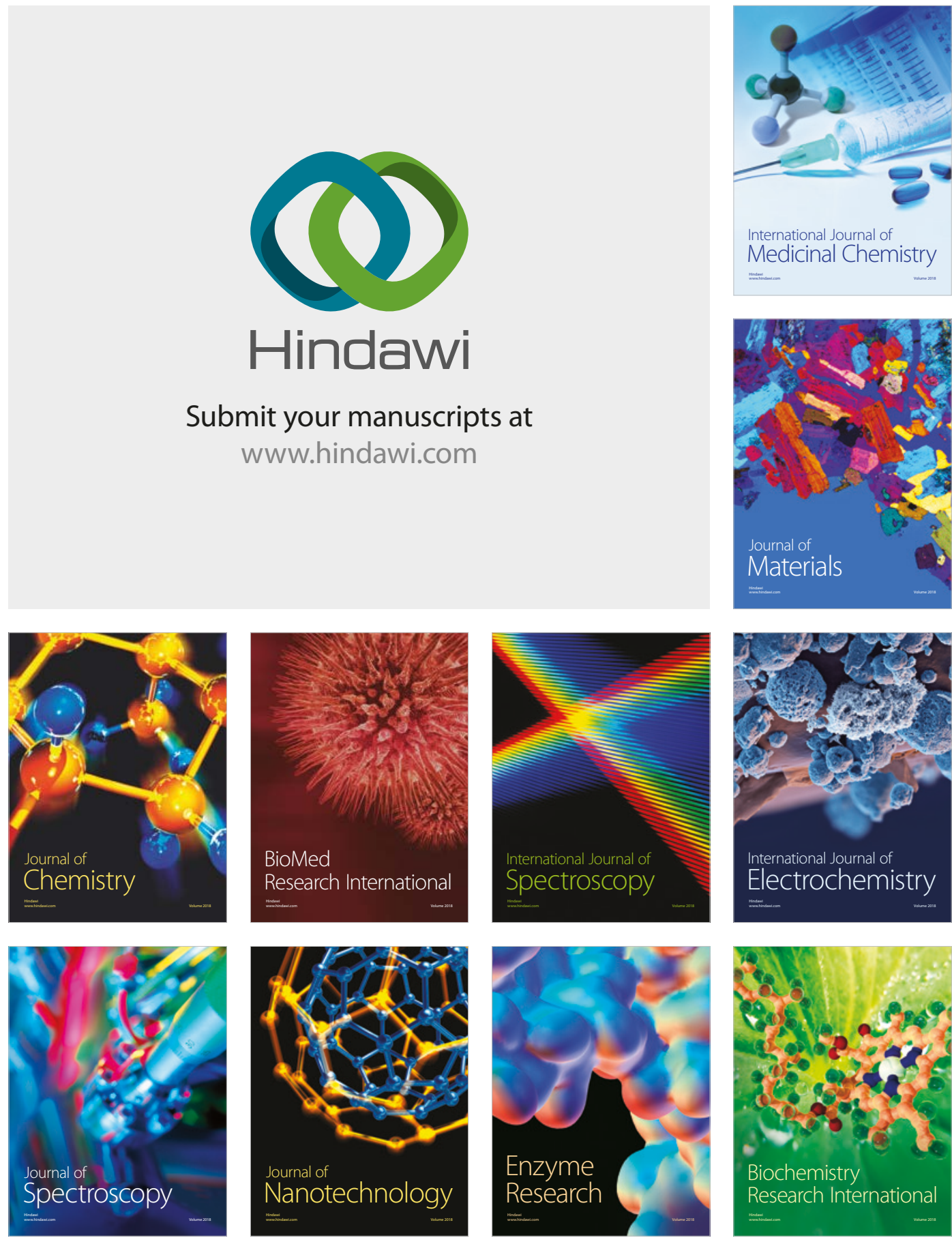
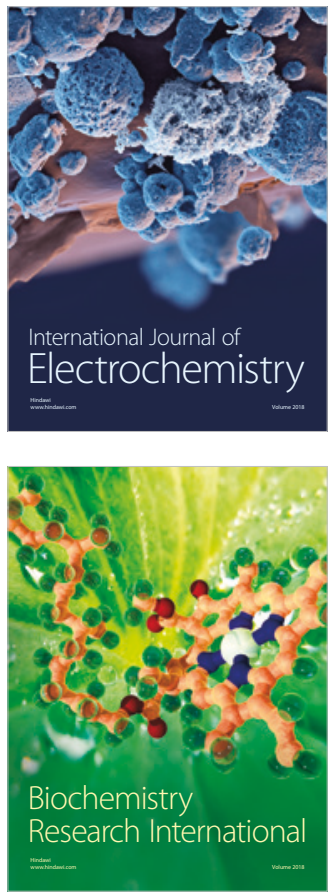